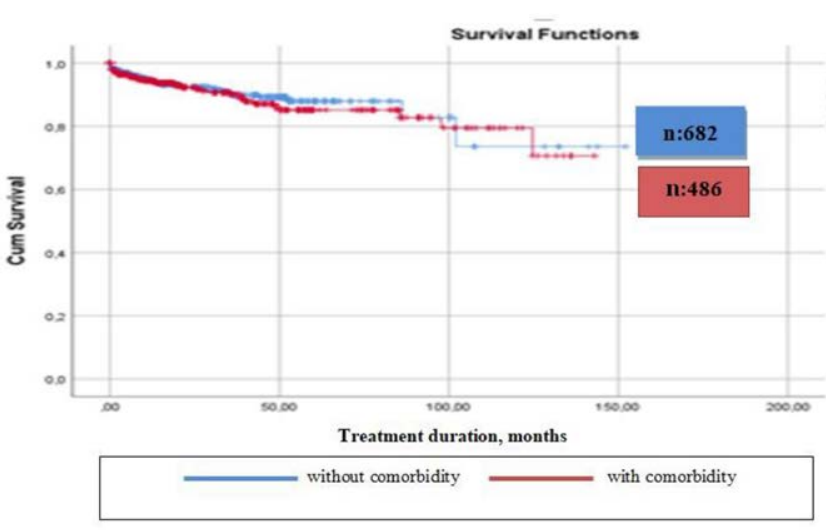

Figure 1. Drug survival of initial TNFi in AxSpA patients ( $\mathrm{p}=0.56$ ).

Disclosure of Interests: None declared

DOI: 10.1136/annrheumdis-2020-eular.2925

\section{THU0379 REDUCTION OF ANTERIOR UVEITIS FLARES IN PATIENTS WITH AXIAL SPONDYLOARTHRITIS FOLLOWING ONE YEAR OF TREATMENT WITH CERTOLIZUMAB PEGOL: 48-WEEK INTERIM RESULTS FROM A 96-WEEK OPEN-LABEL STUDY}

I. Van der Horst-Bruinsma ${ }^{1}$, R. Van Bentum ${ }^{1}$, F. Verbraak' ${ }^{1}$, T. Rath$^{2}$,

J. Rosenbaum ${ }^{3,4}$, M. Misterska-Skora ${ }^{5}$, B. Hoepken ${ }^{6}$, O. Irvin-Sellers ${ }^{7}$,

B. Vanlunen ${ }^{8}$, L. Bauer ${ }^{6}$, M. Rudwaleit ${ }^{9}, 10 .{ }^{7}$ Amsterdam University Medical Center, Amsterdam, Netherlands; ${ }^{2}$ St Franziskus-Hospital, Münster, Germany;

${ }^{3}$ Devers Eye Institute, Portland, United States of America; ${ }^{4}$ Oregon Health and Science University, Portland, United States of America; ${ }^{5}$ Wroclaw Medical University, Wroclaw, Poland; ${ }^{6}$ UCB Pharma, Monheim am Rhein, Germany; ${ }^{7}$ UCB Pharma, Slough, United Kingdom; ${ }^{8}$ UCB Pharma, Raleigh, United States of America; ${ }^{9}$ Klinikum Bielefeld and Charité, Berlin, Germany; ${ }^{10}$ Ghent University, Ghent, Belgium

Background: Acute anterior uveitis (AAU), inflammation of the anterior uveal tract, is reported in up to $40 \%$ of patients (pts) with axial spondyloarthritis (axSpA). ${ }^{1}$ AAU is associated with significant clinical burden; symptoms include blurred vision, photophobia and pain. ${ }^{2}$ Previous studies have shown that TNF inhibitors (TNFi) can reduce AAU flare incidence in pts with radiographic axSpA, ${ }^{3-}$ ${ }^{5}$ but few have focused on pts across the full axSpA spectrum.

Objectives: To analyse the impact of certolizumab pegol (CZP) treatment on AAU in pts with active radiographic and non-radiographic axSpA and a recent history of AAU.

Methods: C-VIEW (NCT03020992) is an ongoing multicentre, open-label, phase 4 study. Pts had active axSpA according to the ASAS classification, a history of recurrent AAU ( $\geq 2$ AAU flares in total and $\geq 1$ AAU flare in the year prior to study entry), were HLA-B27 positive, and were eligible for TNFi treatment (previous failure of $\geq 2$ NSAIDs, biologic naïve or had failed $\leq 1 \mathrm{TNFi}$ ). Pts received CZP $400 \mathrm{mg}$ at Weeks (Wks) 0/2/4, then $200 \mathrm{mg}$ every two wks (Q2W) to Wk 96 . The primary variable was incidence of AAU flares compared to historic rates. A pre-specified interim analysis compared AAU incidence in the $48 \mathrm{wks}$ prior to CZP treatment with the 48 wks of treatment, using Poisson regression adjusted for possible within-pt correlations, with period (pre- and post-baseline) and axSpA disease duration as covariates. Incidence rates (IR) were calculated based on the number of cases/pts at risk over 48 wks. Observed data are reported.

Results: Of 115 enrolled pts, 89 initiated CZP treatment; 85 completed Wk 48. Baseline characteristics are shown in the Table. The 48-wk interim analysis revealed significantly fewer AAU flares/pt during CZP treatment vs before treatment (Figure; Poisson-adjusted IR: 0.2 vs $1.5, p<0.001$ ). The number of pts experiencing 1 and $\geq 2$ AAU flares $(64.0 \%$ and $31.5 \%$ respectively) substantially reduced during CZP treatment (12.4\% and 2.2\%). After 48 wks CZP treatment, disease activity improved substantially (mean \pm SD Ankylosing Spondylitis Disease Activity Score [ASDAS]: $2.0 \pm 0.9$; Bath Ankylosing Spondylitis Disease Activity Index [BASDAI]: $3.3 \pm 2.1$ ), with $31.4 \%$ pts achieving ASAS partial remission and $29.1 \%$ ASDAS major improvement. No new safety signals were identified.
Table. Baseline characteristics

CZP $200 \mathrm{mg}$ Q2W (N=89)

\begin{tabular}{lc}
\hline Age (years), mean \pm SD & $46.5 \pm 11.2$ \\
Male, $\mathrm{n}(\%)$ & $56(62.9)$ \\
Racial group, $\mathrm{n}(\%)$ & \\
$\quad$ Caucasian & $87(97.8)$ \\
Other & $2(2.2)$ \\
Diagnosis, $\mathrm{n}(\%)$ & $76(85.4)$ \\
$\quad$ Radiographic axSpA & $13(14.6)$ \\
$\quad$ Non-radiographic axSpA & $8.6 \pm 8.4$ \\
Duration of axSpA (years), mean \pm SD & $9.9 \pm 9.0$ \\
Time since onset of first uveitis flare (years), mean \pm SD & $3.5 \pm 0.9$ \\
ASDAS, mean \pm SD & $6.5 \pm 1.5$ \\
BASDAI, mean \pm SD & \\
\hline
\end{tabular}

Conclusion: In this open-label study, AAU flare rate significantly reduced in axSpA pts with a history of recurrent AAU during the first 48 wks of CZP. Pts also experienced substantial improvements in axSpA disease activity. References:

[1] Martin TM. Curr Opin Rheumatol 2002;14:337-41

[2] Bacchiega ABS. Rheumatology (Oxford) 2017;56:2060-7

[3] van der Heijde D. Rheumatology (Oxford) 2017;56:1498-509

[4] van Bentum RE. J Rheumatol 2019;46:153-9

[5] van Denderen JC. J Rheumatol 2014;41:1843-8

Figure: (A) Mean number of acute anterior uveitis flares experienced by patients in C-VIEW and (B) proportion of patients experiencing 1,2 or $\geq 3$ acute anterior uveitis flares
A)

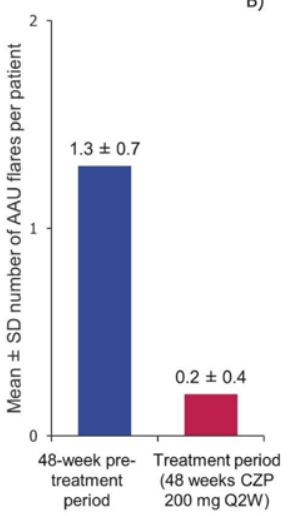

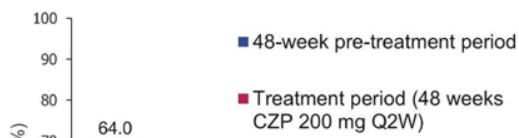
CZP $200 \mathrm{mg} \mathrm{Q2W)}$

AAU: acute anterior uveitis; CZP: certolizumab pegol; Q2W: every 2 weeks; SD: standard deviation.

Acknowledgments: This study was funded by UCB Pharma. Editorial services were provided by Costello Medical.

Disclosure of Interests: Irene van der Horst-Bruinsma Grant/research support from: AbbVie, Novartis, Eli Lilly, Bristol-Myers Squibb, MSD, Pfizer, UCB Pharma Consultant of: AbbVie, Novartis, Eli Lilly, Bristol-Myers Squibb, MSD, Pfizer, UCB Pharma, Rianne van Bentum: None declared, Frank Verbraak Grant/research sup port from: Bayer, Novartis, IDxDR, UCB Pharma, Consultant of: Bayer, Novartis, IDxDR, UCB Pharma, Thomas Rath Grant/research support from: AbbVie, Bristol-Myers Squibb, Chugai, Eli Lilly, MSD, Novartis, Pfizer, Roche, UCB Pharma James Rosenbaum Consultant of: AbbVie, Corvus, Eyevensys, Gilead, Novartis Janssen, Roche, UCB Pharma; royalties from UpToDate, Maria Misterska-Skora: None declared, Bengt Hoepken Employee of: UCB Pharma, Oscar Irvin-Sellers Employee of: UCB Pharma, Brenda VanLunen Employee of: UCB Pharma, Lars Bauer Employee of: UCB Pharma, Martin Rudwaleit Consultant of: AbbVie, BMS Celgene, Janssen, Eli Lilly, MSD, Novartis, Pfizer, Roche, UCB Pharma DOI: 10.1136/annrheumdis-2020-eular.3747

\section{THU0380 SECUKINUMAB IS FREQUENTLY PREFERRED IN MULTI ANTI-TNF RESISTANCE SPONDYLOARTHRITIS PATIENTS: HUR-BIO REAL LIFE RESULTS}

B. Armagan ${ }^{1}$, L. Kılıç ${ }^{1}$, G. K. Yardımcı ${ }^{1}$, E. Bilgin ${ }^{1}$, B. Farisoğulları ${ }^{1}$, E. C. Bolek ${ }^{1}$ E. Duran ${ }^{1}$, O. Karadag ${ }^{1}$, A. Akdoğan ${ }^{1}$, Ş. A. Bilgen ${ }^{1}$, A. İ. Ertenli' ${ }^{1}$, U. Kalyoncu ${ }^{1}$, S. Kiraz ${ }^{1} .{ }^{1}$ Hacettepe University, Faculty of Medicine, Rheumatology, Ankara, Turkey

Background: Anti-TNF agents have been used for the last two decades. However, targeting interleukin-17 (secukinumab (SEC)) is a relatively novel treatment 